\title{
Clinical practice trends in cryosurgery: a retrospective study of cutaneous lesions
}

\author{
Fatma Sule Afsar ${ }^{1}$, Ceren Dagar Erkan ${ }^{1}$, Semsettin Karaca² \\ ${ }^{1}$ Department of Dermatology, Ataturk Research and Training Hospital, Izmir, Turkey \\ Head of the Department: Assoc. Prof. Fatma Sule Afsar MD \\ 2Department of Dermatology, Katip Celebi University, School of Medicine, Izmir, Turkey \\ Head of the Department: Prof. Semsettin Karaca MD
}

Postep Derm Alergol 2015; XXXII, 2: 88-93

DOI: $10.5114 /$ pdia.2015.48048

\begin{abstract}
Introduction: Cryosurgery is an alternative treatment for many benign, premalignant, and malignant lesions of the skin.

Aim: To review the indications of cryosurgery for cutaneous lesions.

Material and methods: The retrospective study was based on the assessment of medical records of 1031 dermatology patients who had cryosurgery.

Results: One thousand two hundred and forty-four sessions of cryosurgery were applied to the total of 1031 patients. Of the 1031 patients, the most frequent indication for cryosurgery was common warts which were present in 535 (61.59\%) patients, followed by anogenital warts in 119 (11.54\%) patients, callosity in 81 (7.85\%) patients, actinic keratosis in 77 (7.46\%) patients, molluscum contagiosum in 35 (3.39\%) patients, and other benign or malignant skin lesions.

Conclusions: Cryosurgery is still a valuable treatment of choice in various benign, premalignant, and malignant skin diseases but seems to be underused for indications other than viral warts.
\end{abstract}

Key words: cryosurgery, diagnosis, skin, indication.

\section{Introduction}

Cryosurgery, well-aimed and controlled destruction of diseased tissue by application of cold, is an effective and efficient method for treating benign, premalignant, and malignant cutaneous lesions [1, 2].

Sun damaged skin and sun-induced neoplasms are amenable to treatment with cryosurgery. Solar keratoses, solar lentigines, sebaceous hyperplasia, colloid milium, diffusely pigmented skin, and fine wrinkles of solar aging all respond to cryosurgery. The mechanism of treatment involves inducing tissue damage, vascular stasis and occlusion, as well as inflammation, to destroy unwanted tissue. After destruction of epidermal lesions, healing involves rapid re-epithelization over a relatively cold-insensitive dermal network [3].

Cryosurgery is easily performed in the office setting, produces excellent cosmetic results, and is well tolerat- ed. Potential adverse effects include infection, hypopigmentation or hyperpigmentation, scarring, and hair loss; however serious reactions are rare [4].

Its disadvantages are the lack of histologic control considering the completeness of this treatment and the relative long period of wound healing. A contraindication to cryosurgery is the location, such as the central part of the face, hairy scalp, and eyebrows, which poses an increased risk for scarring alopecia, and the lower legs and feet due to the risk of ulceration [5].

\section{Aim}

The literature contains studies involving cryosurgery applications in the management of specific skin diseases and their cure rates and complications. The aim of this study was to retrospectively analyze the indications of cryosurgery for cutaneous lesions in clinical practice.

Address for correspondence: Fatma Sule Afsar, Department of Dermatology, Ataturk Research and Training Hospital, 2040 Sok. Kugu 122 D:50 35540, Mavisehir Karsiyaka Izmir, Turkey, phone: +90 532 2958536, e-mail: suleafsar@hotmail.com Received: 17.07.2014, accepted: 10.09.2014. 


\section{Material and methods}

The present study included the diagnoses of patients who had been treated with cryosurgery in the Department of Dermatology, Ataturk Research and Training Hospital, Izmir, Turkey. The retrospective study was based on the assessment of medical records from December 2011 through March 2012. We included all patients who had cryosurgery during this period. No ethical issues had to be taken into consideration and all patient names were kept confidential.

Age and sex of the patients, histopathological examination, if present, and number of treatment sessions were assessed. The results are shown descriptively, aiming to establish the indications for cryosurgery and their frequencies.

Cryosurgery was performed using a liquid nitrogen spray. The open spray technique was used in all patients. Pretreatment with local anesthesia was not applied routinely. A povidone-iodine topical solution was prescribed for every patient and oral analgesic was prescribed if needed after the intervention.

The limitation of the study was the short study period.

\section{Results}

One thousand two hundred and forty four sessions of cryosurgery were applied to the total of 1031 patients. The mean of treatment sessions was 1.18 for all patients. The patients were 588 males and 443 females. The mean age of the patients was 34 (range: 1-93) years. Of the 1031 patients, 989 (95.92\%) had had clinical diagnoses before cryosurgery. In 42 (4.07\%) patients, cryosurgery had been performed after confirmation of the diagnosis by the histopathological examination (Table 1). No minor or major side effects had been defined in medical records of the patients.

Of the 1031 patients, the most frequent indication for cryosurgery was common warts. The distribution of the indications was as follows: common warts in 635 (61.59\%) patients, anogenital warts in 119 (11.54\%) patients, callosity in 81 (7.85\%) patients, actinic keratosis in 77 (7.46\%) patients, molluscum contagiosum in 35 (3.39\%) patients, unspecified benign neoplasms of the skin in 33 (3.20\%) patients, seborrheic keratosis in 24 (2.32\%) patients, basal cell carcinoma in 12 (1.16\%) patients, keloidal scar in $3(0.29 \%)$ patients, hemangioma in $3(0.29 \%)$ patients, cutaneous leishmaniasis in $2(0.19 \%)$ patients, pyogenic granuloma in $2(0.19 \%)$ patients, ingrown nail in $2(0.19 \%)$ patients, epidermal cyst in 1 (0.09\%) patient, prurigo nodularis in $1(0.09 \%)$ patient, and squamous cell carcinoma in $1(0.09 \%)$ patient (Table 2$)$. Depending on the type of lesions, the total freeze time and freeze thaw cycles (FTCS) applied were as follows: common and anogenital warts (one to two 10-60 seconds' FTC), callosity (one 10-15 seconds' FTC), actinic keratosis (one $5-20$ seconds' FTC), molluscum contagiosum (one 5-10 seconds' FTC), seborrheic keratosis (one to two 10-15 seconds' FTC), basal cell carcinoma (two to three 60-90 seconds' FTC), keloidal scar (one to three 30 seconds' FTC), hemangioma (one 10 seconds' FTC), cutaneous leishmaniasis (two 15-20 seconds' FTC), pyogenic granuloma (one $15 \mathrm{sec}$ onds' FTC), ingrown nail (one 30 seconds' FTC), prurigo nodularis (three 10-30 seconds' FTC), and squamous cell carcinoma (two 60-90 seconds' FTC).

\section{Discussion}

Cryosurgery is one of well-established, older therapies and is still widely used [5]. It has advantages over the other modalities. Preparation time is short, and treatment requires no expensive supplies or injectable anesthesia. The risk of infection is low, wound care is minimal, and suture removal is not needed [6].

Contraindications to cryosurgery generally relate to the intercurrent illness such as blood dyscrasias of unknown origin, cold intolerance, Raynaud's disease, cold

Table 1. The indications which had been histopathologically confirmed before cryosurgery

\begin{tabular}{lcc}
\hline Indications & Number of patients & $\begin{array}{c}\text { Number of patients confirmed by the } \\
\text { histopathologic examination }(\mathbf{N}=42) \\
n(\%)\end{array}$ \\
\hline Actinic keratosis & 77 & $19(24.67)$ \\
\hline Unspecified benign neoplasms of skin & 33 & $1(3.03)$ \\
\hline Seborrheic keratosis & 24 & $4(16.66)$ \\
\hline Basal cell carcinoma & 12 & $11(91.66)$ \\
\hline Hemangioma & 3 & $3(100)$ \\
\hline Cutaneous leishmaniasis & 2 & $2(100)$ \\
\hline Prurigo nodularis & 1 & $1(100)$ \\
\hline Squamous cell carcinoma & 1 & $1(100)$
\end{tabular}


Table 2. Distribution of the indications of the patients who had been treated with cryosurgery and number of treatment sessions

\begin{tabular}{|c|c|c|}
\hline Indications & $\begin{array}{c}\text { Number of patients }(N=1031) \\
n(\%)\end{array}$ & $\begin{array}{l}\text { Number of treatment sessions }(N=1244) \\
n \text { (mean) }\end{array}$ \\
\hline \multicolumn{3}{|l|}{ Benign lesions: } \\
\hline Common warts & $635(61.59)$ & $794(1.25)$ \\
\hline Anogenital warts & $119(11.54)$ & $141(1.18)$ \\
\hline Callosity & $81(7.85)$ & $87(1.07)$ \\
\hline Molluscum contagiosum & $35(3.39)$ & $39(1.11)$ \\
\hline Seborrheic keratosis & $24(2.32)$ & $26(1.08)$ \\
\hline Keloidal scar & $3(0.29)$ & $3(1)$ \\
\hline Hemangioma & $3(0.29)$ & $3(1)$ \\
\hline Pyogenic granuloma & $2(0.19)$ & $2(1)$ \\
\hline Cutaneous leishmaniasis & $2(0.19)$ & $3(1.50)$ \\
\hline Ingrown nail & $2(0.19)$ & $2(1)$ \\
\hline Epidermal cyst & $1(0.09)$ & $1(1)$ \\
\hline Prurigo nodularis & $1(0.09)$ & $1(1)$ \\
\hline Unspecified benign neoplasms of skin & $33(3.20)$ & $38(1.15)$ \\
\hline \multicolumn{3}{|l|}{ Premalignant lesions: } \\
\hline Actinic keratosis & $77(7.46)$ & $91(1.18)$ \\
\hline \multicolumn{3}{|l|}{ Malignant lesions: } \\
\hline Basal cell carcinoma & $12(1.16)$ & $12(1)$ \\
\hline Squamous cell carcinoma & $1(0.09)$ & $1(1)$ \\
\hline
\end{tabular}

urticaria, cryoglobulinemia, pyoderma gangrenosum, and collagen and autoimmune disease [3].

Correct clinical diagnosis and lesion selection are critical before performing cryosurgery [7]. Its use in cutaneous malignancies has been previously established. In addition, a broad range of benign problems are potentially amenable to cryosurgery [3]. Benign skin lesions that are suitable for cryosurgery include actinic keratosis, viral wart, molluscum contagiosum, and dermatofibroma [7]. While many lesions respond to single treatment, several treatments may be necessary for some lesions [6].

Common warts were by far the most frequent skin lesions (61.59\%) which had been treated with cryosurgery in this study. It has been reported that cryosurgery was recommended as the first-line therapy for flat and common warts. Cryosurgery has also been suggested as the second-line therapy for common and flat warts on the face [8]. The effectiveness of liquid nitrogen used by the traditional method in the treatment of common warts depend on multiple factors: wart's duration, number of warts, and number of treatments. These factors depend on each other and the overall success rate is approximately $75 \%[7,9]$.
Treating warts with cryosurgery weekly cleans them more rapidly than treating them every 2 to 3 weeks, but the overall cure rate depends on the total number of treatments rather than the interval [10].

Anogenital warts were the second frequent indication (11.54\%) for cryosurgery in the study. Cryosurgery still remains one of the most effective treatments of external genital warts [11]. It has been found to be effective in the management of condyloma accuminatum, particularly when treatment with podophyllin has failed or the lesion is located on the area where use of this agent is undesirable [7]. It has been reported that clinical resolution had been achieved in $69 \%$ and $67 \%$ of male and female patients with anogenital warts, respectively [12]. Care should be exercised where the dermis is thin, such as on the penile shaft, where shorter freeze times are appropriate to avoid damaging tissue underneath lesions [11]. Cryosurgery is the safest treatment for genital warts in pregnant women [13].

Callosity was the third indication (7.8\%) for which cryosurgery had been frequently used. Corns and calluses result from hyperkeratosis, a normal physiologic 
response of the skin to chronic excessive pressure or friction. A mainstay of palliative treatment is sharp debridement to reduce the amount of hyperkeratotic tissue [14]. Instead, cryosurgery has been commonly used in our patients with or without pretreatment with keratolytics.

Actinic keratosis was another indication (7.46\%) for treatment with cryosurgery. The procedure is highly effective, with reported cure rates between $75 \%$ and $99 \%$ [15, 16]. It is best for treating thin, well-demarcated lesions and can be used to treat solitary lesions or small numbers of scattered lesions [4]. Both the spray and contact techniques have been successfully used and one session is usually sufficient, however long-term recurrences are common [1].

Molluscum contagiosum which is a common viral infection, especially in children, was one of the indications (3.39\%) for cryosurgery. Applying a liquid nitrogen spray for a few seconds until the surface of the umbilicated papule returns white usually is adequate [7]. One described technique involves a light freeze until the lesion turns white and then the whole lesion is removed with a small curette. Scarring is unusual with this technique [17].

A range of benign disorders such as milia, syringoma, trichoepithelioma, skin tag, and sebaceous hyperplasia are amenable to cryosurgery [3]. Cryosurgery had been applied to $3.20 \%$ of the patients in whom the diagnosis was defined as unspecified benign neoplasms. Any area of the body can be treated and there are no age limitations [1]. Cryosurgery causes selective destruction of different cell or tissue types, depending on the temperature reached. The collagen-containing connective tissue types are more resistant to cryo-damage than the epidermal cell types, especially melanocytes and deeper epidermal cell layers [18].

Seborrheic keratosis, the most common benign neoplasm, is best treated with cryosurgery or shave excision/ curettage [7]. Cryosurgery was found to be the treatment of choice in some patients $(2.32 \%)$ in the study. It is especially effective in patients with multiple lesions [19]. Thin, flat lesions usually require only 5 to 10 seconds' FTC; larger thicker lesions may need longer treatment times, or occasionally, two FTCs. In treating seborrheic keratosis, the physician should consider the potential for hair loss in treated areas when choosing a therapeutic modality [7].

Cryosurgery is also indicated for malignant skin tumors which include tumors with well-circumscribed borders such as basal cell carcinoma (BCC), squamous cell carcinoma (SCC), Kaposi's sarcoma, and non-operable disseminated cutaneous metastases of malignant melanoma [1]. In the study, cryosurgery had been found to be applied to the patients with BCC (1.16\%). Cryosurgery tends to be the most useful in the treatment of low-risk BCCs, although good results have been reported following treatment of high-risk lesions, either as sole treatment or in combination with curettage [20]. However,
BCCs that are small, have distinct margins, and are in readily accessible areas can be successfully treated with cryosurgery [11]. Five-year cure rates of $99 \%$ have been reported for these lesions [21]. A biopsy should be done to confirm the diagnosis [22]. Freezing should include a 5-mm margin around them and a double FTC produces the best results for BCC $[11,23]$. Cryosurgery had been applied to only 1 patient with SCC (0.09\%) in the study. The reported 5-year cure rate for SCC treated by cryosurgery is $93 \%$ [24]. This method is especially useful for treating tumors in elderly or debilitated patients [25]. An estimation of the extent of the tumor, which can sometimes be difficult should be undertaken before treatment with cryosurgery and a lateral spread of freezing of at least $1 \mathrm{~cm}$ beyond the tumor margins is required to increase the security of the treatment $[1,26]$. Follow-up has to exceed 5 years after treatment at least, and, if possible, to be life-long for both BCC and SCC [1].

Although keloid scar (0.29\%) was not an indication that cryosurgery had been frequently applied in the study, cryosurgery has been shown to produce significantly better results than intralesional triamcinolone [27]. Because of its major advantage of a low relapse rate, cryosurgery, either as monotherapy or in combination, has been established as the treatment of choice for hyperkeratotic scars and keloids [1]. It has been reported that as a single modality, cryosurgery caused complete resolution with no recurrence in $51-74 \%$ of patients after 30 months of follow-up [28]. The resistance to cold of fibroblasts and collagen has been blamed for the difficulty in treatment of keloids with cryosurgery [3]. Best responses were noted when three or more consecutive treatments were used [29]. Treatments should be repeated every 20-30 days [28].

Vascular lesions are treatable with cryosurgery [3]. Hemangioma was the other indication for cryosurgery in a small number of patients (0.29\%) in the study. The treatment of cavernous and capillary hemangiomas is somewhat more difficult, because their variation in size and depth requires modifications to the freezing time [3]. However, it has been reported that capillary hemangiomas of the newborns could show excellent response to contact cryosurgery and usually disappear within 4 weeks [1]. Cryosurgery had been applied to only 2 patients $(0.19 \%)$ with pyogenic granuloma, another vascular tumor. Although excisional surgery is the treatment of choice for pyogenic granuloma, cryosurgery has been reported to be one of the alternative therapies [30].

Cryosurgery had been applied to 2 patients with cutaneous leishmaniasis (0.19\%) in the study. It has been reported that employing liquid nitrogen using a cotton-tipped application with two 15-20 seconds' FTC over three sessions repeated at intervals of 3 weeks had results comparable with antimonials [31].

In the study, $2(0.19 \%)$ patients were found to have cryosurgery done for ingrown nails. Cryosurgery which 
Table 3. Side effects, factors affecting the response, and overall success rates of cryosurgery for cutaneous lesions

\begin{tabular}{|c|c|c|c|}
\hline Diagnosis & Side effects & Factors affecting the response & Overall success rate \\
\hline Common warts & Blistering, pain [9] & Size of wart and degree of hyperkeratosis $[17,34]$ & $75 \%[7,9]$ \\
\hline Anogenital warts & $\begin{array}{c}\text { Pain, hypo- or } \\
\text { hyperpigmentation [35] }\end{array}$ & $\begin{array}{l}\text { Individual wart area, duration, and anatomic site } \\
\text { [36] }\end{array}$ & $67-69 \%[12]$ \\
\hline Actinic keratosis & Hypopigmentation [37] & Duration of freezing [37] & $75-79 \%[15,16]$ \\
\hline Seborrheic keratosis & $\begin{array}{l}\text { Hypopigmentation, } \\
\text { atrophic scar [7, 38] }\end{array}$ & $\begin{array}{l}\text { Thickness of the seborrheic keratosis, freeze time, } \\
\text { and number of FTCs [39] }\end{array}$ & $96.6 \%[38]$ \\
\hline Basal cell carcinoma & $\begin{array}{l}\text { Poor cosmetic outcome } \\
{[20]}\end{array}$ & $\begin{array}{l}\text { Localization, size, and histological type of the } \\
\text { tumor, history of previous recurrence, safety } \\
\text { margins and duration of follow-up [7] }\end{array}$ & $99 \%[21]$ \\
\hline Squamous cell carcinoma & Hypopigmentation [25] & Size and risk of the lesion [40] & $93 \%[24]$ \\
\hline Keloidal scar & $\begin{array}{l}\text { Hypopigmentation, } \\
\text { blistering, delayed healing, } \\
\text { and infection [41] }\end{array}$ & $\begin{array}{c}\text { Number of cryosurgery sessions and duration of } \\
\text { the lesions [1] }\end{array}$ & $61 \%[29]$ \\
\hline
\end{tabular}

is a quick and simple nail sparing procedure that can be carried out without anesthesia with limited facilities for ingrown nails, has been reported to have a rate of success comparable with that of surgical nail sparing procedures, and produces rapid relief of pain in most cases [32].

Epidermal cyst and prurigo nodularis were the other indications for cryosurgery in the study, but cryosurgery had been applied to 1 patient (0.09\%) for each indication. Cryosurgery is a widely used option in the treatment of prurigo nodules. It can take up to 4 weeks until the treated nodules heal, but residual scarring can occur. After cryosurgery, patients can be pruritus free for up to 3 months [33].

Cryosurgery with liquid nitrogen leads to varying success rates and side effects when applied to cutaneous lesions depending on the factors affecting the response (Table 3). It is time saving, relatively inexpensive, and easy to perform by experienced hands [5]. But it does not yield the immediate results of more destructive procedures such as electrodessication, radiofrequency, lasers, and non-tissue sparing excisional surgeries. It also fails to provide the objective histological evidence of tumor removal available with Mohs or excisional surgery [42]. These treatment modalities may be applied, when cryosurgery fails or immediate results or histological evidence are required for skin lesions.

Cryosurgery is still a valuable treatment of choice in various benign, premalignant, and malignant skin diseases but seems to be underused for indications other than viral warts although it is available almost in all secondary and tertiary dermatology units and covered by general health insurance in the country where the study was carried out. However, if we consider that the mean treatment sessions was low for both all patients and indications, it can be stated that the overall success of cryosurgery was good for all indications and no more sessions had been needed for treatment. This study summarizes the skin diseases that had been treated with cryosurgery and attracts attention to the degree of functionality, results, and possible complications related with this treatment modality.

\section{Conflict of interest}

The authors declare no conflict of interest.

\section{References}

1. Zouboulis CC. Cryosurgery in dermatology. Eur J Dermatol 1998; 8: 466-74.

2. Kuflik EG. Cryosurgery updated. I Am Acad Dermatol 1994; 31: 925-44.

3. Thai K, Sinclair RD. Cryosurgery of benign skin lesions. Australas I Dermatol 1999; 40: 175-86.

4. McIntrye WJ, Downs MR, Bedwell SA. Treatment options for actinic keratoses. Am Fam Physician 2007; 76: 667-71.

5. Kuijpers DI, Thissen MR, Berretty PJ, et al. Surgical excision versus curettage plus cryosurgery in the treatment of basal cell carcinoma. Dermatol Surg 2007; 33: 579-87.

6. Guidelines of care for cryosurgery. American Academy of Dermatology Committee on Guidelines of Care. J Am Acad Dermatol 1994; 31: 648-53.

7. Andrews MD. Cryosurgery for common skin conditions. Am Fam Physician 2004; 69: 2365-72.

8. Sterling JC, Handfield-Jones S, Hudson PM; British Association of Dermatologists. Guidelines for the management of cutaneous warts. Br J Dermatol 2001; 144: 4-11.

9. Khaled A, Ben Romdhane S, Kharfi M, et al. Assessment of cryotherapy by liquid nitrogen in the treatment of hand and feet warts. Tunis Med 2009; 87: 690-2.

10. Bourke JF, Berth-Jones J, Hutchinson PE. Cryotherapy of common viral warts at intervals of 1, 2 and 3 weeks. Br J Dermatol 1995; 132: 433-6.

11. Wetmore SJ. Cryosurgery for common skin lesions. Treatment in family physicians' offices. Can Fam Physician 1999; 45: 964-74.

12. Chan YC, Ng KY, Chan RK. The epidemiology and treatment of anogenital warts in Singapore: a retrospective evaluation. Ann Acad Med Singapore 2002; 31: 502-8.

13. Mayeaux EJ Jr, Harper MB, Barksdale W, Pope JB. Noncervical human papilloma virus genital infections. Am Fam Physician 1995; 52: 1137-46. 
14. Freeman DB. Corns and calluses resulting from mechanical hyperkeratosis. Am Fam Physician 2002; 65: 2270-80.

15. Lubritz RR, Smolewski SA. Cryosurgery cure rate of actinic keratoses. J Am Acad Dermatol 1982; 7: 631-2.

16. Szeimies RM, Karrer S, Radakovic-Fijan S, et al. Photodynamic therapy using topical methyl 5-aminolevulinate compared with cryotherapy for actinic keratosis: a prospective, randomized study. J Am Acad Dermatol 2002; 47: 258-62.

17. Lubritz RR. Cryosurgical approach to benign and precancerous tumors of the skin. In: Cryosurgery for skin cancer and cutaneous disorders. Zacarian SA (ed). Mosby, St. Louis 1985; 83-97.

18. Gage AA. What temperature is lethal for cells? J Dermatol Surg Oncol 1979; 5: 459-60, 464.

19. Luba MC, Bangs SA, Mohler AM, Stulberg DL. Common benign skin tumors. Am Fam Physician 2003; 67: 729-38.

20. Smith V, Walton S. Treatment of facial Basal cell carcinoma: a review. J Skin Cancer 2011; 2011: 380371. doi: 10.1155/2011/380371.

21. Graham GF. Advances in cryosurgery during the past decade. Cutis 1993; 52: 365-72.

22. Graham GF. Cryosurgery. Clin Plast Surg 1993; 20: 131-47.

23. Holt PJ. Cryotherapy for skin cancer: results over a 5-year period using liquid nitrogen spray cryosurgery. Br I Dermatol 1998; 119: 231-40.

24. Kuflik EG, Gage AA. The five-year cure rate achieved by cryosurgery for skin cancer. I Am Acad Dermatol 1991; 24: $1002-4$.

25. Neville JA, Welch E, Leffell DJ. Management of nonmelanoma skin cancer in 2007. Nat Clin Pract Oncol 2007; 4: 462-9.

26. Kuflik EG. Cryosurgery for skin cancer: 30-year experience and cure rates. Dermatol Surg 2004; 30: 297-300.

27. Layton AM, Yip J, Cunliffe WJ. A comparison of intralesional triamcinolone and cryosurgery in the treatment of acne keloids. Br J Dermatol 1994; 130: 498-501.

28. Rusciani L, Rossi G, Bono R. Use of cryotherapy in the treatment of keloids. J Dermatol Surg Oncol 1993; 19: 529-34.

29. Zouboulis CC, Blume U, Büttner P, Orfanos CE. Outcomes of cryosurgery in keloids and hypertrophic scars. A prospective consecutive trial of case series. Arch Dermatol 1993; 129: 1146-51.

30. Jafarzadeh H, Sanatkhani M, Mohtasham N. Oral pyogenic granuloma: a review. J Oral Sci 2006; 48: 167-75.

31. al-Majali O, Routh HB, Abuloham O, et al. A 2-year study of liquid nitrogen therapy in cutaneous leishmaniasis. Int J Dermatol 1997; 36: 460-2.

32. Sonnex TS, Dawber RP. Treatment of ingrowing toenails with liquid nitrogen spray cryotherapy. Br Med J (Clin Res Ed) 1985; 291: 173-5.

33. Waldinger TP, Wong RC, Taylor WB, Voorhes JJ. Cryotherapy improves prurigo nodularis. Arch Dermatol 1984; 120: 1598600.

34. Gibbs S, Harvey I, Sterling JC, Stark R. Local treatments for cutaneous warts. Cochrane Database Syst Rev 2003; 3: CD001781.

35. Bonnez W, Oakes D, Bailey-Farchione A, et al. A randomized, double-blind, placebo-controlled trial of systemically administered interferon-alpha, -beta, or -gamma in combination with surgery for the treatment of condylama acuminatum. J Infect Dis 1995; 171: 1081-9.

36. Stone KM, Becker TM, Hadgu A, Kraus SJ. Treatment of external genital warts: a randomised clinical trial comparing podophyllin, cryotherapy, and electrodessication. Genitourin Med 1990; 66: 16-9.
37. Thai KE, Fergin $P$, Freeman $M$, et al. A prospective study of the use of cryosurgery for the treatment of actinic keratoses. Int J Dermatol 2004; 43: 687-92.

38. Tunca M, Tastan HB, Sutman K. The efficacy of cryotherapy in the treatment of seborrheic and solar keratosis. T Klin Dermatoloji 1997; 7: 170-6.

39. Herron MD, Bowen AR, Krueger GG. Seborrheic keratoses: a study comparing the standard cryosurgery with topical calcipotriene, topical tazarotene, and topical imiquimod. Int J Dermatol 2004; 43: 300-2.

40. Firnhaber JM. Diagnosis and treatment of Basal cell and squamous cell carcinoma. Am Fam Physician 2012; 86: 161-8.

41. Zouboulis CC, Orfanos CE. Cryosurgical treatment of hypertrophic scars and keloids. Hautarzt 1990; 41: 683-8.

42. Abramovits W, Goldstein AM, Gonzalez S. Confocal microscopy oriented cryosurgery. Int J Dermatol 2002; 41: 284-5. 